\title{
O ESPANHOL NO PROGRAMA IDIOMA SEM FRONTEIRAS NA UNIVERSIDADE FEDERAL DO MARANHÃO: UMA ANÁLISE DE EXPERIÊNCIA DO ENSINO DO ESPANHOL PARA A INTERNACIONALIZAÇÃO ACADÊMICA
}

\author{
Thiago Augusto dos Santos de JESUS ${ }^{1}$
}

\begin{abstract}
RESUMO
Este artigo tem a finalidade de analisar a experiência recente da implementação da língua espanhola no Programa Idioma Sem Fronteiras na Universidade Federal do Maranhão para atender às necessidades de mobilidade acadêmica dos alunos da graduação, técnicos-administrativos e professores de outras áreas de conhecimento. $\mathrm{O}$ curso tem o objetivo de desenvolver as habilidades linguísticas fundamentais para a comunicação em eventos acadêmicos internacionais e a preparação para exames de certificação internacional de aprendizagem do espanhol como o DELE e o SIELE, além de favorecer o contato da comunidade acadêmica com a cultura e a produção científica dos países de língua espanhola. Para tanto, utilizou-se, como metodologia, um estudo de caso situacional, por meio da análise da perspectiva dos sujeitos participantes do curso Bem-Vindo ao Espanhol: língua Internacional, da proposta didática utilizada pelo Núcleo de Línguas da Universidade Federal do Maranhão e do material produzido pelo Núcleo para o desenvolvimento das habilidades linguísticas de nível A1. Para a realização da análise de experiência docente, este trabalho ampara-se nos novos estudos de letramentos para a aprendizagem de línguas, segundo Street (2004) e Heath (2004), as práticas de letramento são atividades generalizadoras e abstratas no que se referem aos comportamentos relacionados com o uso da leitura e da escrita em contextos específicos de comunicação e na orientação da avaliação das habilidades linguísticas do MCER (2002). Essa experiência permitiu que, no decorrer do processo, houvesse uma percepção de aprendizagem do idioma voltada para a diversidade linguística do espanhol e para as necessidades de integração acadêmica dos estudantes universitários a nível internacional.
\end{abstract}

PALAVRAS-CHAVES: Idioma Sem Fronteiras. Internacionalização. Espanhol com fins acadêmicos. Experiência docente.

\section{THE SPANISH LANGUAGE AT THE LANGUAGES WITHOUT BORDERS PROGRAMME OF FEDERAL UNIVERSITY OF MARANHÃO: AN ANALYSIS EXPERIENCE OF TEACHING SPANISH LANGUAGE FOR SCHOLAR INTERNATIONALIZATION}

\begin{abstract}
The present paper aims to analyze the recent experience related to the inclusion of Spanish language at the Languages Without Borders programme of Federal University of Maranhão to meet necessities of higher education mobilization to college students, civil servants, and professors of another knowledge fields. The development of fundamental linguistic skills to communication at international graduation events and organization of international certification test in learning of Spanish language like DELE and SIELE are the main objectives of course that intend to approximate the higher education institution to culture and scientific studies development of Spanish-speaking countries. The methodology used to organization this paper, however, was a situational case study through

\footnotetext{
${ }^{1}$ Universidade Federal do Maranhão (UFMA), São Luís - MA - Brasil. Doutor em Educação. Professor de língua espanhola. ORCID <https://orcid.org/0000-0003-3463-4610>. E-mail: espanhol.ncl@gmail.com
} 
perspective analysis of attending subjects at the course Welcome to Spanish: international language, teaching proposal used for Language Teaching Institute of Federal University of Maranhão, and material produced by institute as a way to improve the linguistic skills in level A1. This article is related to new studies of literacy for a language learning; according to Street (2004) and Heath (2004), the activities of practical literacy are generalized and abstract in relation to behaviors linked to reading and writing in specific contexts of communication and guidance of linguistic skills test made by MCER (2002). This experience allowed there was, during the process, a learning insight geared linguistic diversity and necessities of scholar integration of Spanish language to college students.

Keywords: Languages Without Borders. Internationalization. Spanish language for scholar studies. Experience in education.

\section{EL ESPAÑOL EN EL PROGRAMA IDIOMA SIN FRONTERAS EN LA UNIVERSIDAD FEDERAL DE MARANHÃO: UN ANÁLISIS DE EXPERIENCIA DE LA ENSEÑANZA DE ESPAÑOL PARA LA INTERNACIONALIZACIÓN ACADÉMICA}

\section{Resumen}

Este artículo tiene la finalidad de analizar la experiencia reciente de la implementación de la lengua española en el Programa Idioma Sin Fronteras en la Universidad Federal de Maranhão para atender a las necesidades de movilidad académica de los alumnos de graduación, técnicos-administrativos y profesores de otras áreas de conocimiento. El curso tiene el objetivo de desarrollar las habilidades lingüísticas fundamentales para la comunicación en eventos académicos internacionales y la preparación para exámenes de acreditación internacional de aprendizaje de español como DELE y SIELE, además de favorecer el contacto de la comunidad académica con la cultura y la investigación científica de los países hispanohablantes. Para ello, se utilizó, como metodología, un estudio de caso situacional, por medio del análisis de la perspectiva de los sujetos participantes del curso Bienvenido al español: Lengua Internacional, de la propuesta didáctica utilizada por el Núcleo de Lenguas de la Universidad Federal de Maranhão y del material producido por el Núcleo para el desarrollo de habilidades lingüísticas de nivel A1. Para la realización del análisis de experiencia docente, este trabajo se sostiene en los nuevos estudios de literacidad para el aprendizaje de lenguas, según Street (2004) y Heath (2004), las prácticas letradas son actividades generalizadoras y abstractas en lo que se refieren a los comportamientos relacionados con el uso de la lectura y de la escrita en contextos específicos de comunicación y en la orientación de la evaluación de las habilidades lingüísticas del MCER (2002). Dicha experiencia permitió que, durante el proceso. hubiese una percepción de un aprendizaje del idioma vuelto a la diversidad lingüística del español y a las necesidades de integración académica de estudiantes universitarios a nivel internacional.

Palabras clave: Idioma Sin fronteras. Internacionalización. Español con fines académicos. Experiencia docente.

\section{Introdução}

De modo geral, o Programa Idioma Sem Fronteiras (ISF) tem como objetivo promover políticas linguísticas para a internacionalização do Ensino Superior, através da oferta de cursos presenciais e não presenciais de línguas estrangeiras modernas como o inglês, o espanhol, o francês, o alemão e o português como língua estrangeira.

Além disso, o ISF desenvolve uma política de formação especializada de professores de línguas estrangeiras por meio de residência docente, cursos de atualização didática e testes 
de proficiência. Dessa forma, o programa visa capacitar professores, estudantes e técnicosadministrativos das instituições federais de ensino, desenvolvendo as habilidades linguísticas fundamentais para a realização das atividades acadêmicas em âmbito internacional.

Dada à importância da internacionalização das instituições de ensino superior do país, consideramos pertinente discutir os processos de internacionalização e os programas desenvolvidos para promover a participação de estudantes e servidores em geral em programas de graduação e pós-graduação no Exterior (FINARDI e PREBIANCA, 2014; LUCE, FAGUNDES e GONZÁLEZ MEDIEL, 2016).

Considerando a política de formação de professores de línguas estrangeiras do ISF, analisar-se-ão os princípios teórico-metodológicos para a atualização didática desses professores que atuam nos cursos de línguas estrangeiras do programa, como o enfoque adotado, a abordagem de ensino, as concepções de língua e linguagem, as habilidades linguísticas desenvolvidas nas aulas e as orientações pedagógicas na elaboração do material didático (CASSANY, LUNA e SANZ, 1994; CONSEJO DE EUROPA, 2002).

Para avaliar a experiência da primeira turma de espanhol para iniciantes do Programa Idioma Sem Fronteiras da Universidade Federal do Maranhão, apresentar-se-ão os resultados do questionário aplicado com os alunos sobre a metodologia utilizada nas aulas e a aprendizagem da língua espanhola no que se refere às habilidades linguísticas propostas para o nível A1.

Nas próximas seções, abordaremos minuciosamente como funciona o Programa Idioma Sem Fronteiras na Universidade Federal do Maranhão, principalmente, no que se refere à implementação da língua espanhola e ao perfil dos estudantes de graduação que participam do curso no Campus Bacanga, em São Luís, Maranhão.

\section{A internacionalização nas Instituições de Ensino Superior}

Antes de realizar a abordagem sobre a internacionalização nas Instituições de Ensino Superior, há uma discussão no mundo acadêmico sobre as fronteiras conceituais entre a globalização e a internacionalização, assim como seus efeitos nas políticas linguísticas e educacionais implementadas no Ensino Superior nos últimos anos.

De acordo com o novo dicionário Aurélio da língua portuguesa (2009), a globalização é um "processo que ocasiona uma integração, ou uma ligação estreita entre economias e mercados, em diferentes países, resultando na quebra das fronteiras entre eles". Assim, podemos afirmar que a globalização está diretamente relacionada com os acordos políticos e 
econômicos para o livre comércio entre países. Em contrapartida, o termo internacionalização refere-se à condição de tornar-se internacional, ou seja, independente das relações econômicas e políticas existentes entre países.

Para Held e McGrew (1999), a globalização pode interferir de maneira diferente, de acordo com cada país, porque cada país apresenta suas especificidades culturais, históricosociais e suas prioridades. Nesse caso, as decisões tomadas e as ações realizadas num determinado país podem influenciar, e inclusive, determinar encaminhamentos em outras regiões distintas do mundo.

Na concepção de Morosoni (2006), a internacionalização estabelece uma relação entre universidade e conhecimento e também podem abranger outros pontos focais como a globalização e a transnacionalização ${ }^{2}$ etc.

Dessa forma, a internacionalização do ensino superior representa as relações de poder e hegemonia no mundo globalizado, refletindo nas políticas educacionais e linguísticas adotadas pelas instituições de ensino superior, portanto, o processo de internacionalização se adequa às necessidades do mercado de trabalho e às exigências dos países que controlam a economia e a política no mundo globalizado.

Apesar da internacionalização possuir sua abrangência no campo da universidade e do conhecimento, esse processo não ocorre de maneira igual em todos os contextos, porque depende dos acordos internacionais firmados entre os países e dos objetivos pretendidos no campo do ensino, da extensão e da pesquisa das instituições de ensino superior. Isso nos leva a reconhecer dois tipos de internacionalização: a internacionalização ativa e a internacionalização passiva. Na visão de Amorim e Finardi (2017), a internacionalização ativa ocorre quando há políticas de recepção de acadêmicos (mobilidade do tipo IN) e a oferta de programas de graduação, pós-graduação e extensão no exterior como a exportação e instalação de campi em outros países, enquanto que a internacionalização passiva não há uma política clara de internacionalização para o envio de alunos para outros países (mobilidade do tipo OUT) por não dispor de recursos humanos e financeiros para receber e ofertar programas educacionais em seus países de origem.

A partir do reconhecimento da dualidade da internacionalização, podemos afirmar que o processo de internacionalização é bastante complexo no que se refere ao seu desenvolvimento nas instituições de ensino superior ao longo do tempo, passando por várias

\footnotetext{
${ }^{2}$ A transnacionalização é um processo formado a partir da internacionalização da economia e da cultura, mas que dá alguns passos além a partir da primeira metade do século XX, ao gerar empresas e movimentos cuja sede não se encontra exclusiva e predominantemente numa única Nação (CANCLINI, 2003)
} 
etapas. Segundo Morosoni (2006), a internacionalização passa por três etapas distintas: a) dimensão internacional - presente no século XX acontecendo de maneira acidental nas instituições de ensino superior sem um planejamento prévio e uma organização para a realização de programas de mobilidade acadêmica internacional; b) educação internacional acontece nos Estados Unidos, entre a segunda guerra mundial e o fim da guerra fria, por razões políticas e de segurança nacional; e c) internacionalização da educação superior acontece após a guerra fria e com objetivos estratégicos relacionados com a globalização e a regionalização das sociedades e seu impacto no ensino superior.

No Brasil, o programa de internacionalização acontece de forma descentralizada, desenvolvendo alguns programas de mobilidade acadêmica através de convênios firmados entre universidades estrangeiras para a realização de programas de ensino, pesquisa e extensão entre as instituições. Segundo Laus (2012), isso se torna mais evidente com a criação do Ciências sem Fronteiras, programa de pesquisa criado em 26 de julho de 2011 pela presidente Dilma Rousseff, cujo objetivo era favorecer aos estudantes das ciências exatas e tecnológicas com bolsas de iniciação científica em universidades de prestígio internacional no campo da pesquisa e da inovação tecnológica.

Sobre a internacionalização das universidades, Martins e Reis (2015) citam os fatores que elevam o nível desse programa nas instituições de ensino superior, assim, os seguintes fatores são: a) número de estudantes estrangeiros em um determinado campus; b) o número e a magnitude da investigação internacional; c) projetos internacionais de investigação cooperativas; d) parcerias internacionais envolvendo assistência às universidades estrangeiras e outras instituições; e) universidades privadas e parcerias do setor com as metas internacionais, cooperação internacional e colaboração entre escolas e faculdades; e f) a extensão da infusão internacional no conteúdo curricular.

Na próxima seção, analisaremos o programa Idioma sem Fronteiras como projeto educacional da internacionalização da Universidade Federal do Maranhão e sua dimensão na oferta do ensino do inglês, do espanhol e do português como língua estrangeira.

\section{O Espanhol no ISF no contexto da Universidade Federal do Maranhão}

Inicialmente, o programa Idioma sem Fronteiras na Universidade Federal do Maranhão ofertava somente cursos presenciais de língua inglesa para a comunidade acadêmica nos Campi de São Luís, Pinheiro, Imperatriz e Bacabal. A partir de 2018, o NucliUFMA iniciou a oferta de dois cursos presenciais - o espanhol e o português como língua 
estrangeira para a comunidade acadêmica do Campus São Luís, atendendo às necessidades de alunos estrangeiros da pós-graduação e de alunos da graduação que almejam participar de programas de mobilidade acadêmica internacional em países de língua espanhola.

Com respeito à língua espanhola, o Nucli-UFMA ofereceu na oferta $\mathrm{H}$ o curso Bemvindo ao Espanhol: Língua Internacional, com a carga horária de 32 horas, cujo objetivo é o de promover as habilidades linguísticas fundamentais de nível A1, além de mostrar a relevância da língua de Cervantes no contexto acadêmico internacional.

Para a Universidade Federal do Maranhão, o curso Bem-vindo ao Espanhol: Língua Internacional ofereceu 25 vagas para uma única turma, funcionando como um projeto piloto para a oferta de outras turmas para o ano de 2019, pois a intenção do Nucli-UFMA é oferecer em cada oferta do programa Idioma sem Fronteiras uma turma de língua espanhola para consolidar o processo de ensino-aprendizagem desse idioma no Campus São Luís e a aplicação de exames de certificação internacional do espanhol como o SIELE.

$\mathrm{Na}$ primeira oferta de espanhol do ISF-UFMA, as vagas para o curso se esgotaram no primeiro dia de inscrições, gerando uma lista de espera com 16 alunos interessados. Isso revela que a língua inglesa não é o idioma dominante no mundo acadêmico e existe uma demanda de interessados em participar de eventos acadêmicos, programas de graduação e pós-graduação em países de língua espanhola, além de obter conhecimentos do idioma para fins específicos.

Entre os participantes da primeira oferta do curso de espanhol do ISF-UFMA, participam alunos da graduação de várias áreas de conhecimento como demostra o quadro abaixo:

Quadro 1 - Síntese de alunos de espanhol ISF por curso de graduação

\begin{tabular}{|c|c|}
\hline CURSOS DE GRADUAÇ̃̃O & NÚMERO DE ALUNOS POR CURSO \\
\hline Enfermagem & 1 \\
\hline Ciências Contábeis & 5 \\
\hline Biblioteconomia & 2 \\
\hline Letras & 6 \\
\hline Pedagogia & 1 \\
\hline Nutrição & 2 \\
\hline Geografia & 1 \\
\hline Biologia & 3 \\
\hline Turismo & 1 \\
\hline Odontologia & 1 \\
\hline
\end{tabular}




\begin{tabular}{|c|c|}
\hline Filosofia & 2 \\
\hline & Total $=25$ alunos \\
\hline
\end{tabular}

Fonte: Elaboração própria (2019)

Por meio do quadro 1, podemos afirmar que o interesse pela aprendizagem da língua espanhola no Programa Idioma sem Fronteiras na Universidade Federal do Maranhão não é exclusivamente dos alunos de graduação dos Centros de Ciências Humanas e Sociais, mas também dos alunos do Centro de Ciências Biológicas e da Saúde, mostrando a necessidade de ampliar o programa para atender mais alunos com a oferta de cursos em horários diferentes durante a semana.

De acordo com a proposta pedagógica do Programa Idioma sem Fronteiras, o curso de espanhol deve considerar os aspectos funcionais, linguísticos e interculturais no conteúdo programático, de modo que os alunos possam desenvolver competências e habilidades comunicativas básicas ao desenvolvimento social em contextos de internacionalização. Assim, mencionamos os seguintes aspectos:

a) Aspectos funcionais: manejar a linguagem cotidiana; apresentar-se adequadamente em diferentes situações de comunicação: no âmbito pessoal, público e profissional; perguntar por um objeto; perguntar e informar sobre a localização; expressar preferências; perguntar e informar a frequência com que se realizam determinadas atividades cotidianas, falar de horários e rotinas.

b) Aspectos linguísticos: usos de verbos no presente do indicativo; identificação e uso dos gêneros do adjetivo e formação do plural; uso dos pronomes pessoais e de tratamento; contraste entre os verbos Ser e Estar; uso das contrações das preposições, dos advérbios muy e mucho.

c) Aspectos interculturais: diferenças entre o registro pronominal (português e espanhol da Espanha e da América Latina) e aspectos relativos às normas de cortesias entre os hispanos e os brasileiros.

Esses aspectos demostram a relevância das relações sociais e culturais nas práticas de linguagem no âmbito da comunicação internacional, trazendo-nos a importância de analisar os aspectos ideológicos e as relações de poder existentes nas estruturas linguísticas na vida social, refletindo, portanto, no letramento dos aprendizes de um idioma (STREET, 2004).

Por essa razão, as práticas de letramento englobam não somente as atividades de linguagem que envolvem a escrita, mas também outras habilidades linguísticas que identificam as visões de mundo específicas de um grupo social e cultural, como afirma o teórico do letramento sociocultural: 
O letramento é visto como um conjunto de práticas discursivas, ou seja, como formas de usar a língua e outorgar sentido tanto na fala como na escrita. Estas práticas discursivas estão ligadas a visões de mundo (crenças e valores) de determinados grupos sociais ou culturais. ${ }^{3}$ (GEE, 2004, p.24)

Dessa forma, é impossível desenvolver práticas discursivas no âmbito da internacionalização sem considerar os valores e as visões dos grupos sociais e culturais que são falantes da língua espanhola. Por essa razão, o programa de língua espanhola do ISF trata dos aspectos interculturais para que os participantes dos programas de mobilidade acadêmica da Universidade Federal do Maranhão possam compreender as interações comunicativas por meio da interação verbal e estabeleça essa interação no plano da alteridade. Assim,

O eu e o outro são, cada um, no universo de valores. O mesmo mundo, quando correlacionado comigo ou com o outro, recebe valores diferentes, é determinado por diferentes quadros axiológicos. E essas diferenças são arquitetonicamente ativas, no sentido de que são constitutivas dos nossos atos (inclusive de nossos enunciados): é na contraposição de valores que os atos concretos se realizam; é no plano dessa contraposição axiológica (é no plano da alteridade, portanto) que cada um orienta seus atos. (FARACO, 2009, p. 21-22).

Nessa perspectiva, o enfoque adotado, a abordagem de ensino, as concepções de língua e linguagem e as habilidades linguísticas desenvolvidas no curso de espanhol do ISF/UFMA são demostradas no quadro abaixo:

Quadro 2 - Síntese da metodologia de ensino de espanhol ISF/UFMA

\begin{tabular}{|c|c|c|c|}
\hline Enfoque & Abordagem & Língua/Linguagem & Habilidades linguísticas \\
\hline $\begin{array}{l}\text { Orientado à ação, } \\
\text { considerando } \\
\text { recursos cognitivos, } \\
\text { emocionais } \\
\text { volitivos para que } \\
\text { os aprendizes sejam } \\
\text { um agente social. }\end{array}$ & Sociointeracionista. & $\begin{array}{lr}\text { Língua } & \text { como } \\
\text { interação } & \text { social/ } \\
\text { Linguagem } & \text { como } \\
\text { processo } & \text { de } \\
\text { interlocução. } & \end{array}$ & $\begin{array}{l}\text { Expressão oral } \\
\text { Compreensão oral } \\
\text { Expressão escrita } \\
\text { Compreensão escrita }\end{array}$ \\
\hline
\end{tabular}

Fonte: Elaboração própria (2019)

Por meio do enfoque por tarefas, os aprendizes da língua espanhola se transformam em agentes sociais na realização das atividades cotidianas que envolvem a linguagem na resolução de problemas por meio da elaboração de gêneros textuais escritos de uso nos contextos sociais (CONSEJO DE EUROPA, 2002). Esse enfoque e essa abordagem de ensino de língua desenvolvem uma interação entre os sujeitos e o contexto sociocultural,

\footnotetext{
${ }^{3}$ La literacidad es vista como un conjunto de prácticas discursivas, es decir, como formas de usar la lengua y otorgar sentido tanto en el habla como en la escritura. Estas prácticas discursivas están ligadas a visiones del mundo específicas (creencias y valores) de determinados grupos sociales o culturales. (GEE, 2004, p.24)
} 
sendo, portanto, um sistema de representação de valores e de identidade social e cultural dos sujeitos (BARTON e HAMILTON, 2004).

Com a finalidade de que a comunidade acadêmica desenvolva práticas comunicativas em língua espanhola em contexto internacional, as instituições de ensino superior necessitam romper as barreiras culturais e ideológicas existentes entre o Brasil e alguns países de língua espanhola da América Latina para que as trocas de conhecimentos e as experiências entre esses estudantes e esses povos sejam enriquecedoras do ponto de vista da aprendizagem da língua e de outros conhecimentos relacionados com a pesquisa científica. Desse modo, adverte-se que:

A menos que as fronteiras entre as salas de aula e as comunidades possam romper-se e se estimule o fluxo de padrões culturais entre elas, as escolas continuarão legitimando e reproduzindo as comunidades que controlam e limitam o progresso potencial de outras comunidades e que permanecem desconectadas de outros valores e modos de vida. (HEATH 1983 apud IVANIC e MOSS, 2004, p. 215) ${ }^{4}$

Para romper as fronteiras entre o espaço de aprendizagem e os países de língua espanhola, o Nucli-UFMA orienta aos professores no processo de elaboração do material didático, na seleção de materiais para o desenvolvimento das habilidades linguísticas e na exposição dos valores sociais e culturais desses países. As orientações são as seguintes:

- Os textos sonoros para o desenvolvimento da compreensão oral devem apresentar situações de comunicação do cotidiano, explorando tanto a linguagem formal das instituições sociais dominantes como a linguagem informal da rotina de contextos não dominantes.

- A diversidade linguística do espanhol deve aparecer em todos os níveis linguísticos: fonético-fonológico, semântico-lexical e pragmático-discursivo, de modo que os estudantes conheçam a heterogeneidade.

- Os textos selecionados para a compreensão leitora devem apresentar temas de investigação das áreas de conhecimento das ciências sociais, humanas, biológicas e exatas, de modo que esses temas tenham impacto no cotidiano da vida das pessoas em nível global.

- As aulas devem iniciar com as habilidades linguísticas consideradas mais simples - a expressão oral e a compreensão - e posteriormente se desenvolvem as outras habilidades mais complexas - a compreensão escrita e a expressão escrita.

\footnotetext{
${ }^{4}$ Tradução livre do autor do artigo
} 
- Para a realização das atividades em sala de aula, deve selecionar-se materiais autênticos dos países de língua espanhola como anúncios publicitários, propagandas de televisão, notícias de telejornais, entrevistas, etc.

- As habilidades linguísticas devem estar integradas com outras destrezas e competências para que os aprendizes tenham autonomia na construção dos conhecimentos e desempenham a função de agente social do entorno em que vão atuar.

Na seção seguinte, apresentaremos a percepção e a opinião dos alunos em relação à aprendizagem da língua espanhola e a metodologia utilizada pelo Nucli-UFMA para o curso do Idioma sem Fronteiras.

\section{Resultados e discussões}

A partir da experiência docente e da avaliação da comunidade acadêmica respeito à metodologia do curso de espanhol do programa Idioma sem Fronteiras da Universidade Federal do Maranhão, apresentamos os resultados, considerando os seguintes aspectos: (i) o motivo dos alunos pela escolha do curso; (ii) o favorecimento da metodologia do curso ao processo de aprendizagem; e (iii) a percepção dos alunos em relação à sua aprendizagem.

\section{O motivo dos alunos pela escolha do curso Bem-vindo ao espanhol: Língua Internacional}

Considerando a seguinte pergunta do questionário aplicado com os alunos "Por que você se matriculou no curso Bem-vindo ao espanhol: Língua Internacional?”, os alunos apresentaram as razões pelas quais se interessaram pela oferta do espanhol do programa Idioma sem Fronteiras na Universidade Federal do Maranhão, como demostramos no quadro abaixo:

Quadro 3 - Razões de escolha do curso de espanhol ISF/UFMA

\begin{tabular}{|c|c|}
\hline Razões de escolha do curso & Número de alunos \\
\hline Facilidade de aprendizagem do idioma & 25 \\
\hline Preferência do idioma & 20 \\
\hline $\begin{array}{c}\text { Possibilidade de mobilidade acadêmica em } \\
\text { países de língua espanhola }\end{array}$ & 20 \\
\hline $\begin{array}{c}\text { Aprendizagem do idioma para exames de } \\
\text { proficiência }\end{array}$ & 15 \\
\hline $\begin{array}{c}\text { Simpatia pela cultura dos países de língua } \\
\text { espanhola }\end{array}$ & 22 \\
\hline
\end{tabular}




\begin{tabular}{|c|c|}
\hline $\begin{array}{c}\text { Interesse pelos eventos acadêmicos } \\
\text { internacionais }\end{array}$ & 18 \\
\hline $\begin{array}{c}\text { Leitura de obras acadêmicas em língua } \\
\text { espanhola }\end{array}$ & 20 \\
\hline
\end{tabular}

Fonte: Elaboração própria (2019)

Tomando como referência as informações do Quadro 3, podemos afirmar que há unanimidade entre os estudantes das diferentes áreas de conhecimento pela facilidade de aprendizagem da língua espanhola, pois é uma língua que compartilha de regras gramaticais e de vocabulário semelhantes ao português, já que é uma língua proveniente do mesmo tronco linguístico - o latim. Além disso, o português funciona como conhecimento prévio para a aprendizagem de novas informações gramaticais e lexicais do espanhol, promovendo, portanto, uma aprendizagem significativa.

Dos 25 alunos de espanhol do Isf, vinte alunos optaram pelo idioma por questões de preferência em relação ao inglês. Além disso, esses alunos consideram muito mais fácil participar dos exames de seleção para participar de programas de mobilidade acadêmica e de eventos acadêmicos em países de língua espanhola da América do Sul pela proximidade com o território brasileiro e também pelos custos com as passagens e outras despesas referentes à sua manutenção nesses países durante os programas. Esses alunos também relatam o interesse pelo idioma para ter acesso a leituras de textos acadêmicos de autores e pesquisadores de universidades da Espanha e da América Latina.

Outros estudantes relataram o interesse pelo curso de língua espanhola do Isf por causa da aprendizagem de estratégias de leitura de textos acadêmicos para a realização de exames de proficiência para ingresso em cursos de mestrado e de doutorado, além de obter a certificação internacional de acreditação de competências e habilidades no idioma como o DELE e o SIELE.

Com relação à segunda pergunta do questionário "Como a metodologia utilizada no curso de espanhol do ISF favoreceu a sua aprendizagem?", os alunos mencionaram algumas características e estratégias didáticas que favoreceram o desenvolvimento das habilidades linguísticas e facilitaram a aprendizagem do idioma. Desse modo, demostramos essas características e estratégias no quadro seguinte:

Quadro 4 - Favorecimento da metodologia à aprendizagem do espanhol

\begin{tabular}{|c|c|}
\hline Aspectos da metodologia & Número de alunos \\
\hline Atividades lúdicas & 20 \\
\hline $\begin{array}{c}\text { Uso de materiais autênticos da realidade dos } \\
\text { países de língua espanhola }\end{array}$ & 15 \\
\hline Enfase nos aspectos interculturais entre & 12 \\
\hline
\end{tabular}




\begin{tabular}{|c|c|}
\hline Brasil e países de língua espanhola & 18 \\
\hline Pouca abordagem gramatical & 20 \\
\hline $\begin{array}{c}\text { Realização de atividades de âmbito } \\
\text { acadêmico }\end{array}$ & 25 \\
\hline $\begin{array}{c}\text { Organização do tempo de aula para cada } \\
\text { habilidade linguística }\end{array}$ & 22 \\
\hline Comunicação através do whatsapp & 25 \\
\hline Realização de aulas fora do Nucli-UFMA & \\
\hline
\end{tabular}

Fonte: Elaboração própria (2019)

Com base nas informações do Quadro 4, podemos dizer que todos os alunos aprovaram a organização do tempo das aulas para o desenvolvimento das habilidades linguísticas. Nesse caso, a duração de 60 minutos para cada habilidade linguística é suficiente para os alunos pensar, refletir e organizar as informações aprendidas para desenvolver as tarefas pedidas em sala de aula, considerando que o curso de espanhol do Isf da UFMA tinha a duração de 4 horas por semana, portanto, dedicava-se uma hora para cada habilidade linguística. Além disso, os alunos gostaram de aprender a língua espanhola fora da sala de aula, ou seja, em outros espaços em que haja interação e convivência com outras pessoas, possibilitando a troca de experiências e de conhecimentos.

Dos 25 alunos, vinte e dois relataram que a comunicação entre os alunos e o professor do curso através do whatsapp facilitou a aprendizagem de muitas informações relevantes da língua espanhola, como a ortografia de muitas palavras do idioma, o emprego adequado do acento ortográfico, o uso de tempos verbais e conectores textuais. Isso complementou os aspectos gramaticais, já que estes aspectos não eram muito abordados em sala de aula, para que as aulas não se tornassem muito cansativas pelo fato de acontecer à noite e o objetivo primordial era desenvolver as habilidades comunicativas voltadas para o contexto acadêmico.

No que se refere à terceira pergunta do questionário "Como você avalia seu desempenho no nível Al do curso de espanhol do Isf?", os alunos mencionaram alguns aspectos satisfatórios em relação às habilidades linguísticas desenvolvidas nas aulas e também mencionaram outros aspectos que necessitam melhorar seu desempenho em uma das habilidades linguísticas, como demostra o quadro seguinte:

Quadro 5 - Desempenho nas habilidades linguísticas do espanhol

\begin{tabular}{|lllll|c|}
\hline \multicolumn{2}{|c|}{ Desempenho nas habilidades linguísticas } & Número de alunos \\
\hline $\begin{array}{l}\text { Satisfatório } \\
\text { linguísticas }\end{array}$ & em & todas & as & habilidades & 20 \\
\hline $\begin{array}{l}\text { Satisfatório } \\
\text { linguísticas }\end{array}$ & em & uma & das & habilidades & 15 \\
\hline
\end{tabular}




\begin{tabular}{|l|c|}
\hline Satisfatório em duas habilidades linguísticas & 15 \\
\hline Insatisfatório em uma habilidade linguística & 5 \\
\hline
\end{tabular}

Fonte: Elaboração própria (2019)

Tomando como referência as informações do Quadro 5, podemos dizer que 15 alunos estão satisfeitos com o desempenho em uma das habilidades linguísticas, pois necessitam delas para a realização de exames de seleção de mestrado ou doutorado e também para a leitura de alguns textos acadêmicos e elaboração de resumos para publicação de artigos científicos em revistas de universidades espanholas e latino-americanas. Essas habilidades linguísticas são a compreensão escrita e a expressão escrita, já que estas estão totalmente integradas nas atividades de âmbito acadêmico.

Por outro lado, vinte alunos ficaram satisfeitos com o desempenho em todas as habilidades linguísticas, porque acreditavam que não eram capazes de realizar as tarefas de compreensão oral por razões da entonação e do ritmo de conversação dos espanhóis e dos latino-americanos. Com relação à expressão oral, os alunos relataram que, para os objetivos do nível A1, conseguem comunicar-se com os falantes de língua espanhola sem dificuldades de expressar seus sentimentos e anseios. Por último, as tarefas de expressão escrita e de compreensão escrita foram as mais fáceis para os alunos do curso, porque estes já têm uma vivência com os gêneros textuais exigidos para esse nível, como bilhetes, informativos, emails, anúncios e resumos de trabalhos científicos.

Não obstante, cinco alunos relataram dificuldades com a diversidade linguística do espanhol, por razões da variação linguística do vocabulário e da pronúncia entre os países da América Latina e Espanha, dificultando a compreensão oral e a compreensão escrita de alguns gêneros e, por essa razão, o desempenho insatisfatório nessas habilidades linguísticas.

Finalmente, referente à última pergunta do questionário "Qual é a sua percepção acerca do espanhol após a conclusão do nível A1?, os alunos emitiram as seguintes opiniões sobre suas experiências e vivências nas aulas do curso do Isf, como demostra o quadro seguinte:

Quadro 6 - Percepção dos alunos sobre a língua espanhola após a conclusão do curso

\begin{tabular}{|l|c|}
\hline $\begin{array}{l}\text { Percepção dos alunos sobre a língua } \\
\text { espanhola }\end{array}$ & Número de alunos \\
\hline $\begin{array}{l}\text { Um idioma de relevância para o } \\
\text { contexto acadêmico internacional }\end{array}$ & 20 \\
\hline $\begin{array}{l}\text { Um idioma de relevância para o } \\
\text { contexto brasileiro. }\end{array}$ & 5 \\
\hline $\begin{array}{l}\text { Um idioma motivador para conhecer a } \\
\text { cultura da Espanha e dos países }\end{array}$ & 5 \\
\hline
\end{tabular}


latinos.

Fonte: Elaboração própria (2019)

Com base nas informações do Quadro 6, podemos afirmar que a maioria dos alunos do curso de espanhol do Isf reconheceu a relevância do idioma para a participação dos programas de mobilidade acadêmica em países de língua espanhola, além de eventos acadêmicos promovidos por universidades espanholas e da América Latina. Também alguns alunos consideraram que a fonte de informações para algumas pesquisas se encontra em países da América do Sul, como o Peru e a Colômbia.

Um grupo reduzido de alunos do Isf revelou que o estudo da língua espanhola é importante para os brasileiros, principalmente, para os que vivem em regiões de fronteira, já que o Brasil estabelece relações políticas e econômicas com muitos países de língua espanhola, como é o caso do Paraguai e da Argentina. Além das questões políticas e econômicas, os alunos retificaram a importância do estudo do idioma como elemento enriquecedor para que os brasileiros conheçam melhor a história, a cultura e a identidade dos povos latinos.

\section{Considerações finais}

Consideramos que a primeira experiência da oferta de espanhol pelo programa Idioma sem Fronteiras na Universidade Federal do Maranhão foi positiva porque teve adesão dos estudantes dos cursos de graduação de diferentes áreas de conhecimento e possibilitou reafirmar a presença da língua espanhola como língua adicional ${ }^{5}$ no âmbito da internacionalização acadêmica, retificando sua relevância pelo número de falantes no mundo depois do inglês e do mandarim e pelo crescimento da produção científica das universidades espanholas e da América Latina.

Certamente, a oferta do curso de espanhol do Isf na Universidade Federal do Maranhão possibilitou uma reflexão acerca do processo de formação inicial de professores de espanhol, pelas seguintes razões: dificuldades para selecionar professores para atuar no programa Idioma sem Fronteiras, ausência de cursos de especialização e atualização didática para professores de espanhol no Estado do Maranhão, a escassez de materiais didáticos para o

\footnotetext{
${ }^{5}$ Língua adicional trata-se de uma língua que o aluno aprende por acréscimo, além das que ele já sabe e que, por isso, pode ter como ponto de partida outras línguas, o que sugere possivelmente uma convivência pacífica entre as línguas, já que o domínio de cada uma atende os objetivos diferentes; são conhecimentos que, a priori, não competem entre si, mas se complementam. (LEFFA e IRALA, 2014, p.22)
} 
desenvolvimento de habilidades linguísticas para fins específicos e a falta de visibilidade do espanhol no programa Idioma sem Fronteiras.

Apesar da língua espanhola ter sido ofertada apenas no final do período acadêmico da Universidade Federal do Maranhão, acreditamos que conseguimos alcançar o nosso objetivo de atingir a meta estabelecida pelo MEC de 25 alunos para a formação de uma turma e todos mantiveram a motivação para aprender o idioma desde o início até o final do curso, propondo uma continuação na primeira oferta de cursos do Isf do ano de 2019.

Ressaltamos que o desempenho dos alunos de espanhol do Isf foi algo que nos surpreendeu bastante pelo fato de que teríamos dificuldades de conseguir atender à diversidade da turma, já que se tratava de um grupo heterogêneo, de áreas de conhecimentos e com objetivos distintos de aprendizagem do idioma. Desta forma, conseguimos desenvolver habilidades linguísticas, possibilitando que a maioria dos alunos desenvolvesse as quatro destrezas e saísse apto para comunicar-se em espanhol em qualquer situação comunicativa de A1.

Nesse sentido, acreditamos que o uso do enfoque voltado para as tarefas e a abordagem sociointeracionista permitiram que os alunos aprendessem com autonomia e utilizassem a língua espanhola para a resolução de problemas cotidianos das instituições sociais, desenvolvendo, assim, as práticas de letramento voltadas para todos os âmbitos: acadêmico, pessoal, social e cultural.

Em suma, o espanhol no Programa Idioma sem Fronteiras da Universidade Federal do Maranhão possibilitou não somente agregar conhecimentos do idioma, mas também das relações sociais e culturais dos hispanofalantes, reafirmando, portanto, a presença do idioma no contexto da internacionalização acadêmica.

\section{REFERÊNCIAS}

AMORIM, G. B.; FINARDI, K. R. Internacionalização do ensino superior e línguas estrangeiras: evidências de um estudo de caso nos níveis micro, meso e macro. Avaliação, Campinas, Sorocaba, SP, v.22, n.03, p.614-632, 2017.

BARTON, D.; HAMILTON, M. La literacidad entendida como práctica social. In: In: ZAVALA, V.; NIÑO-MURCIA, M.; AMES, P. (Org.). Escritura y sociedad: nuevas perspectivas teóricas y etnográficas. Lima, Perú: Red para el Desarrollo de las Ciencias Sociales en Perú, p..109-140, 2004.

CANCLINI, N. G. A globalização imaginada. São Paulo: Iluminuras, 2003. 
CASSANY, D.; LUNA, M.; SANZ, G. Enseñar lengua. Barcelona: Graó,1994.

CONSEJO DE EUROPA. Marco Común Europeo de Referencia para las lenguas: enseñanza, aprendizaje y evaluación. Madrid: MECD-Anaya, 2002.

FARACO, C. A. Linguagem e diálogo: as ideias linguísticas do círculo de Bakhtin. São Paulo: Parábola Editorial, 2009.

FERREIRA, A. B. H. Novo dicionário Aurélio da língua portuguesa. $3^{\mathrm{a}}$ ed. São Paulo: Fundação Dorina Nowill para Cegos, 2009.

FINARDI, K. R.; PREBIANCA, G. Políticas linguísticas, internacionalização, novas tecnologias e formação docente: um estudo de caso sobre o curso de Letras Inglês em uma universidade federal. Leitura (UFAL), Alagoas, v.1, p.129-154, 2014.

GEE, J. P. Oralidad y literacidad: de El Pensamiento salvaje a Ways with Words. In: ZAVALA, V.; NIÑO-MURCIA, M.; AMES, P. (Org.). Escritura y sociedad: nuevas perspectivas teóricas y etnográficas. Lima, Perú: Red para el Desarrollo de las Ciencias Sociales en Perú, p..23-56, 2004.

HEATH, S. Ways with words. Cambridge: Cambridge University Press, 1983.

HELD, D.; MCGREW, A. et al. Global Transformations: Politics, Economics and Culture. Cambridge: Polity Press, 1999.

IVANIC, R.; MOSS, W. La incorporación de las prácticas de escritura de la comunidad en la educación. In: ZAVALA, V.; NIÑO-MURCIA, M.; AMES, P. (Org.). Escritura y sociedad: nuevas perspectivas teóricas y etnográficas. Lima, Perú: Red para el Desarrollo de las Ciencias Sociales en Perú, p..211-246, 2004.

LAUS, S. P. A Internacionalização da educação superior: um estudo de caso da Universidade Federal de Santa Catarina. Tese (Doutorado em Administração). Universidade Federal da Bahia, Salvador, p.22 -333, 2012.

LEFFA, V. J.; IRALA, V. B. Uma espiadinha na sala de aula: Ensinando línguas adicionais. Pelotas: Educat, 2014.

LUCE, M. B.; FAGUNDES, C. V.; GONZÁLEZ MEDIEL, O. Internacionalização da educação superior: a dimensão intercultural e o suporte institucional na avaliação da mobilidade acadêmica. Avaliação, Campinas; Sorocaba, v. 21, n. 2, p. 317-339, jul. 2016.

MARTINS, A; REIS, E. C. Internacionalização na UFSC: análise do programa inglês sem fronteiras e do curso extracurricular de inglês. XV Colóquio Internacional de Gestão Universitária - CIGU: Desafios da Gestão Universitária no Século XXI, Mar del Plata, Argentina, 2015.

MOROSONI, M. C. Estado do conhecimento sobre internacionalização da educação superior - conceitos e práticas. Educar, nº 288, p.107-124, 2006. 
STREET, B. Los nuevos estudios de literacidad. In: ZAVALA, V.; NIÑO-MURCIA, M.; AMES, P. (Org.). Escritura y sociedad: nuevas perspectivas teóricas y etnográficas. Lima, Perú: Red para el Desarrollo de las Ciencias Sociales en Perú, p..81-108, 2004. 